\title{
Efficacy and Tolerability of Fluticasone Propionate /Salmeterol MDI Compared With Concurrent Fluticasone Propionate and Salmeterol MDI in Adult Patients with Persistent Asthma: A Randomized, Double-Blind 12-Week Study
}

\author{
Mahesh PA${ }^{1}$, Rebello CJ ${ }^{2 *}$, Purandare $\mathrm{SM}^{2}$, Gogtay JA ${ }^{2}$ and Bill Brashier ${ }^{2}$ \\ ${ }^{1}$ Department of Chest Medicine, Allergy, Asthma \& Chest Research Centre, India \\ ${ }^{2}$ Department of Clinical Research, Cipla Ltd, India
}

Submission: February 21, 2017; Published: September 25, 2017

*Corresponding author: Juliet Rebello, Department of Clinical Research, Cipla Ltd 4th floor, North Block, R\&D Centre, Vikhroli (W), Mumbai - 400 083, India, Tel: +912225756430; Email: juliet@cipla.com

\begin{abstract}
Background: The use of a single inhaler to administer a dry powder formulation of fluticasone (FP) and salmeterol (SM) is at least as effective as concurrent administration of the mono-components from individual dry powder inhalers. Whether the same applies to the pressurised metered dose inhaled (pMDI) formulation of these products which, unlike the dry powder formulations are not breath-actuated, has not been established.
\end{abstract}

Objective: This study assessed the non-inferiority of the combination fluticasone/salmeterol pMDI (Cipla Ltd) versus concurrent administration of fluticasone and salmeterol administered via two separate pMDIs in patients with asthma.

Methods: In this 12-week, randomized, double blind study, patients with mild to moderate persistent asthma were randomized (1:1) to two inhalations twice daily of fluticasone/salmeterol pMDI 125/25 mcg [FP/SM $125 / 25 \mathrm{mcg}]$ or concurrent administration of Flixotide Evohaler and Serevent Evohaler [FP 125mcg and SM 25mcg] for 12 weeks. The primary endpoint was the change from baseline in morning peak expiratory flow rate (mPEFR) at week 12 . Secondary endpoints included change at 12 weeks from baseline in forced expiratory volume in 1 second (FEV), asthma symptom scores, and rescue medication use. Tolerability was also assessed.

Results: Three hundred and sixty subjects (mean age of 41.3 years) were randomized to FP/SM 125/25mcg combination (n=183 patients) or concurrent FP $125 \mathrm{mcg}$ plus SM $25 \mathrm{mcg}$ ( $\mathrm{n}=177$ subjects). Demographic and baseline clinical characteristics including baseline lung function was similar between the 2 groups. The adjusted mean increase at week 12 from baseline (PP population) in mPEFR was 38.7L/min in the FP/ SM 125/25mcg group versus 33.4L/min in the concurrent FP $125 \mathrm{mcg}$ plus SM 25mcg group. The adjusted mean treatment difference was 5.2L/ min and the one sided $97.5 \%$ confidence limit for the treatment difference was -3.6 to $14.0 \mathrm{~L} / \mathrm{min}$. Similar results were observed for the ITT population. At week 12, no significant difference in changes from baseline $\mathrm{FEV}_{1}$, daytime, nighttime asthma symptom scores and rescue medication was observed between the two treatment groups. Overall, adverse events (AEs) and other tolerability measures were comparable between the two groups.

Conclusion: Administration of FP/SM 125/25 HFA pMDI as a combination was at least as effective as concurrent administration of the mono-components in improving overall asthma control in subjects with mild to moderate persistent asthma.

Keywords: Asthma; Fluticasone; salmeterol; Hydrofluoroalkane; Inhaled corticosteroid; Pulmonary function.

Abbreviations: ICS: Inhaled corticosteroids; LABA: Long acting beta2-agonists; FP: Fluticasone propionate; SM: Salmeterol; CFC: Chlorofluorocarbon; HFA: Hydrofluoroalkane; MDI: metered dose inhaler

\section{Introduction}

Asthma affects both children and adults. It is currently estimated that as many as 300 million people worldwide of all ages and all ethnic backgrounds suffer from asthma [1]. Inhaled corticosteroids (ICS) are the drugs of choice for the management of subjects with persistent asthma. Studies have demonstrated that the combination of a long acting beta agonist and an inhaled 
corticosteroid provides better overall asthma control than doubling the dose of inhaled steroids alone [2,3].

The combination of the long acting beta agonist (LABA), salmeterol, and the inhaled corticosteroid (ICS), fluticasone propionate has been shown to be effective and well tolerated in the treatment of persistent asthma [4,5]. Salmeterol/ fluticasone improve lung function and controls symptoms and exacerbations more effectively in subjects with asthma, symptomatic on regular ICSs [6-11]. These effects are thought to be due to the complementary mechanisms of action of fluticasone propionate and salmeterol which interact in a synergistic manner at the receptor, molecular, and cellular levels [12]. For optimal drug interaction, both these drugs should reach the same target cell together in adequate concentrations, which can be achieved by their co administration [13].

Previous studies have shown that the use of a single inhaler to administer a dry powder formulation of fluticasone (FP) and salmeterol (SM) is at least as effective as concurrent administration of the mono-components from individual dry powder inhalers $[14,15]$. Whether the same applies to the pMDI formulation of these products which, unlike the dry powder formulations are not breath-actuated, has not been established.

This study was designed to assess the non-inferiority of a fluticasone/salmeterol HFA pMDI combination (Cipla Ltd) versus concurrent administration of fluticasone and salmeterol administered via two separate inhalers in subjects with asthma.

\section{Material and Methods}

This 12-week, double blind randomized study was conducted at 18 study sites [Trial registration number: CTRI/2010/091/003029]. The study protocol was approved by the ethics committee at each center and, all subjects gave written, informed consent prior to enrolment or performance of any study related procedures. The study was conducted in conformance with the guidelines for ethical treatment of human subjects that have their origin in the Declaration of Helsinki and its amendments and are consistent with the Guideline for Good Clinical practice [ICH GCP E6] and applicable local regulatory requirements.

\section{Inclusion and exclusion criteria}

Male and female subjects eligible for inclusion in the trial were aged 18 to 65 years with persistent asthma, as defined by the GINA 2007 guidelines [16] and using an ICS ( $\geq 400 \mu$ g and $\leq 800 \mu \mathrm{g}$ of beclomethasone dipropionate (BDP) or equivalent per day) for at least 4 weeks prior to study entry. Symptomatic subjects had a pre-bronchodilator forced expiratory volume in one second $\left(\mathrm{FEV}_{1}\right)$ of $\geq 60 \%$ and $\leq 90 \%$ of the predicted normal value and demonstrated $\mathrm{a} \geq 12 \%$ and $200 \mathrm{~mL}$ improvement in $\mathrm{FEV}_{1}$ within 15-30 minutes after inhalation of salbutamol $(400 \mu \mathrm{g})$. All subjects were able to perform the required pulmonary function tests, and demonstrated correct use of the pMDI.
Subjects were excluded if they had any of the following: contraindication to ICS or LABA use; hypersensitivity to the study medications or any of the excipients; lower respiratory tract infection in the last 4 weeks prior to screening; chronic obstructive pulmonary disease or other relevant pulmonary disease other than asthma; any change in asthma therapy (other than inhaled short-acting $\beta 2$ - agonists as rescue medication) or admission to a hospital for the treatment of asthma within 4 weeks; and/or oral or systemic corticosteroid use within 4 weeks before study entry or $>4$ times during the preceding 12 months. Subjects were also excluded if they had a smoking history of $\geq 10$ pack years or clinically relevant abnormal laboratory parameters.

\section{Study design}

This was a randomized, double-blind, double-dummy, parallel group 12-week non-inferiority study comparing a combination pMDI containing hydrofluoroalkane (HFA)-propelled fluticasone propionate $125 \mathrm{mcg}$ and salmeterol $25 \mathrm{mcg}$ (FP/SM 125/25mcg) (Cipla Ltd, India) with two single pMDIs taken concurrently: one containing HFA-propelled fluticasone propionate $125 \mu \mathrm{g}$ (FP 125mcg) (Flixotide Evohaler TM Allen and Hanburys, UK) and the other containing chlorofluorocarbon (CFC)-propelled salmeterol 25 $\mu \mathrm{g}$ (SM 25mcg) (Serevent TM Allen and Hanburys, UK).

Eligible subjects were randomized (1:1) by means of a computer-generated randomization list to receive the fixed dose combination of FP/SM $125 / 25$ mcg or concurrent FP $125 \mathrm{mcg}$ and SM $25 \mathrm{mcg}$. Subjects underwent a 3 to 4 -week run-in period during which they received only short-acting $[\beta 2$-agonist rescue medication (salbutamol as needed) and/or their regular ICS at a constant dose.

Subjects were randomized at the end of the run-in period, if they fulfilled two of the following criteria as recorded in the diary card during the last 7 days of the run-in period.

I. Daytime symptom score (diary data) of $\geq 1$ on any 2 days.

II. Use of short-acting $\beta 2$-agonists more than twice daily on any 2 days.

III. Night-time symptoms score (diary data) of $\geq 1$ on one or more occasion.

Additionally, $\mathrm{FEV}_{1}$ at randomization had to be within $15 \%$ of that recorded at the beginning of the 3 - week run-in and had to remain within the range of $60-90 \%$ predicted.

\section{Study visits}

Clinic visits occurred in the morning at enrollment, after the run-in period (baseline; week 0) and after 3, 6, 9 and 12weeks of treatment. Procedures at each visit included spirometry $\left(\mathrm{FEV}_{1}\right)$ which was performed at the same time of the day (08:00 to 11:00), diary card assessment and vital-signs measurement. 
Safety measures included adverse events (assessed throughout the study), vital signs and clinical laboratory parameters (haematology, clinical chemistry and urinalysis; (assessed at enrolment and at the end of the study).

\section{Efficacy assessments}

The primary efficacy endpoint was the change in mean morning peak expiratory flow (PEF) from baseline (mean of the last 14 days of the run-in period) at week 12. Using a miniWright PEF meter (Clement Clarke International, Ltd., Harlow, United Kingdom), subjects recorded PEF twice daily (in the morning and in the evening at fixed times 12 hours apart). At each time point, 3 readings were obtained with the patient in a standing position. All 3 values were entered into the diary by the patient.

The secondary efficacy end point was the change in spirometry-derived $\mathrm{FEV}_{1}$ from baseline to study end or discontinuation (12 weeks or last observation carried forward [LOCF]) For spirometry assessments, 3 technically acceptable FEV $^{1}$ measurements were performed according to the American Thoracic Guidelines [16] using a calibrated spirometer. All values had to be within $200 \mathrm{~mL}$ of each other. If the difference was larger, measurements were repeated (up to 8 measurements), and the largest value was reported. Asthma scores were recorded on a 4-point scale, as follows: daytime: $0=$ unrestricted usual daily activities, no symptoms to 3 = symptoms severe; not able to perform usual daily activities; nighttime: $0=$ no symptoms, slept through the night to 3 = awake most of the night because of asthma. Diaries were collected at each study visit and were checked by the investigators at each institution to ensure completeness of entries.

\section{Tolerability assessment}

Tolerability was assessed using physical examination, vitalsigns measurements; standard laboratory parameters and assessments of AEs.

\section{Study withdrawal}

Subjects were withdrawn from the study if they had an asthma exacerbation requiring treatment with oral or systemic corticosteroids, or used an asthma medication other than their trial medications and rescue salbutamol

\section{Statistical analysis}

This study was designed to assess the non-inferiority of FP/ SM 125/25mcg and concurrent FP 125mcg plus SM 25mcg. The primary population for assessing non-inferiority was the per-protocol population (PP). Analyses on the intent to treat population (ITT) were also conducted as a supporting analysis. An analysis of covariance with factors for treatment, baseline, gender and age was used to assess non-inferiority. The test for non-inferiority was 1 -sided, at a 0.025 level of significance. Noninferiority of FP/SM 125/25mcg versus concurrent FP 125mcg plus SM $25 \mathrm{mcg}$ was claimed if the lower limit of the $97.5 \% \mathrm{CI}$ for the difference between the treatments exceeded the noninferiority margin of $20 \mathrm{~L} / \mathrm{min}$ for mPEFR. In accordance, a sample size of 132 subjects per treatment group was determined to yield at least $90 \%$ power to show non-inferiority between treatments assuming a common SD of $50 \mathrm{~L} / \mathrm{min}$ and using a 0.025 one-sided significance level.

Differences in the use of rescue medication and in asthma symptom scores (daytime, and nighttime) were analyzed using Cochran-Mantel-Haenszel test adjusted for centre effect.

\section{Results}

\section{Study population}

Among the 460 subjects screened for the study, 360 (ITT population) subjects (151 men, 209 women; mean age, 41.3years) were randomized, of which 183 subjects were randomized to the combination FP/SM $125 / 25 \mathrm{mcg}$ and 177 subjects to concurrent FP $125 \mathrm{mcg}$ plus SM $25 \mathrm{mcg}$, 177 subjects) (Figure 1). The treatment groups were similar with regard to demographics and baseline clinical characteristics (Table 1). Overall, $9(2.5 \%)$ subjects were smokers or ex-smokers and $208(57.7 \%)$ subjects were receiving treatment with an ICS at the time of enrolment. In total, 20 subjects did not complete the study. The most common reasons for not completing the study were protocol violations and withdrawal of consent (Figure 1). There were more subjects who did not complete the study in the concurrent FP $125 \mathrm{mcg}$ plus SM $25 \mathrm{mcg}$ group than in the FP/ SM 125/25mcg group. All results reported below are for the PP population. Results for the ITT population were similar to those of the PP population for all endpoints.

Table 1: Demographic and baseline clinical characteristics of the study subjects (intent-to-treat population)

\begin{tabular}{|c|c|c|}
\hline & $\begin{array}{c}\text { FP+SM 125/25 } \\
(n=183)\end{array}$ & $\begin{array}{l}\text { FP } 125 \text { and SM } 25 \\
\text { taken concurrently } \\
\quad(n=177)\end{array}$ \\
\hline Men/women, \% & $41 / 59$ & $43 / 57$ \\
\hline $\begin{array}{l}\text { Mean age, years } \\
\text { (range) }\end{array}$ & 38.6 (17 to 64$)$ & 39.1 (19 to 64$)$ \\
\hline \multicolumn{3}{|c|}{ Smoking status, n (\%) } \\
\hline Current smokers & $0(0.0)$ & $1(0.6)$ \\
\hline Ex smokers & $2(1.1)$ & $6(3.4)$ \\
\hline Non smokers & $181(98.9)$ & $170(96.0)$ \\
\hline $\begin{array}{l}\text { Baseline mPEFR (L/ } \\
\text { min) Mean (SD) }\end{array}$ & $288.9(77.17)$ & $298.8(89.48)$ \\
\hline $\begin{array}{l}\text { Baseline FEV1 (L) } \\
\text { Mean (SD) }\end{array}$ & $1.901(0.471)$ & $1.927(0.497)$ \\
\hline \multicolumn{3}{|c|}{ Baseline therapy, n(\%) } \\
\hline $\begin{array}{c}\text { Inhaled } \\
\text { corticosteroids }\end{array}$ & 107 (58.4) & $101(57.0)$ \\
\hline Theophyllines & $23(12.5)$ & $15(8.5)$ \\
\hline
\end{tabular}




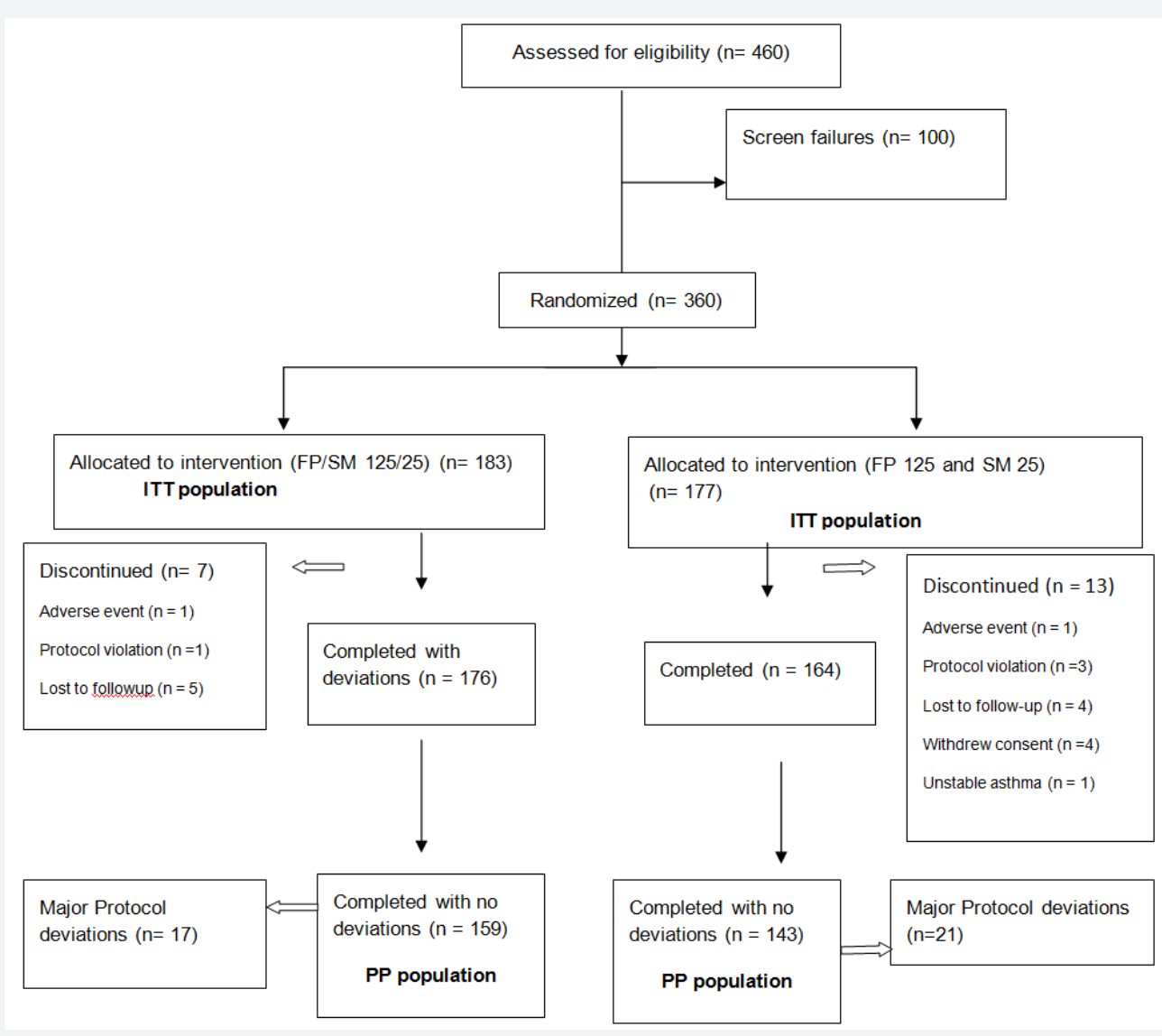

Figure 1: Subject Disposition.

The two treatment groups were similar with regard to treatment compliance, with at least $96 \%$ of subjects in the FP/ SM $125 / 25$ group and at least $94 \%$ of subjects in the FP 125 plus SM 25 group showing treatment compliance.

\section{Efficacy}

\section{Morning peak expiratory flow}

At 12 weeks, the adjusted mean increase in the PP population from baseline in morning $\mathrm{PEF}$ was $38.7 \mathrm{~L} / \mathrm{min}$ in the $\mathrm{FP} / \mathrm{SM} 125 / 25 \mathrm{mcg}$ combination group versus $33.4 \mathrm{~L} / \mathrm{min}$ in the concurrent FP $125 \mathrm{mcg}$ plus SM $25 \mathrm{mcg}$ group. The adjusted mean Table 2: Statistical analyses of PEFR and FEV1 changes with FP/SM 125/25 mcg versus concurrent FP 125mcg plus SM 25mcg (PP population)

\begin{tabular}{|c|c|c|c|c|c|c|}
\hline $\begin{array}{l}\text { Lung Function } \\
\text { Parameter }\end{array}$ & Treatment & $\mathbf{N}$ & $\begin{array}{c}\text { Adjusted Mean Change } \\
\text { From Baseline (95\% } \\
\text { CI) }\end{array}$ & $\begin{array}{l}\text { Mean Treatment } \\
\text { Difference }\end{array}$ & $\begin{array}{l}\text { 95\% Confidence } \\
\text { Interval Of } \\
\text { The Treatment } \\
\text { Difference }\end{array}$ & P-Value \\
\hline \multirow[t]{2}{*}{ mPEFR (L/min) } & FP/SM 125/25 & 157 & $38.7(31.3,46.1)$ & 5.2 & $-3.6,14.0$ & 0.2452 \\
\hline & FP 125 and SM 25 & 141 & $33.4(27.1,39.7)$ & & & \\
\hline \multirow[t]{2}{*}{$\mathrm{FEV}_{1}(\mathrm{~L})$} & FP/SM 125/25 & 157 & $0.131(0.089,0.173)$ & -0.007 & $-0.061,0.047$ & 0.7898 \\
\hline & FP 125 and SM 25 & 141 & $0.137(0.098,0.176)$ & & & \\
\hline
\end{tabular}

treatment difference was $5.2 \mathrm{~L} / \mathrm{min}$ and the one sided $97.5 \%$ confidence limit for the treatment difference was -3.6 to $14.0 \mathrm{~L} /$ min indicating that the combination treatment was non-inferior to the concurrent therapy Table $2 \&$ Table 3 .

\section{Forced expiratory volume in 1 second}

As for PEFR, there was a clinically relevant increase from baseline in $\mathrm{FEV}_{1}$ in both the treatment groups after 12 weeks of treatment. The adjusted treatment difference was $-0.007 \mathrm{~L}$, with a one sided $97.5 \%$ confidence limit of -0.061 to $0.047 \mathrm{~L}$ Table 2 , Figure 2. 
Table 3: Mean mPEFR and FEV1 over 12 weeks ; FP/SM 125/25 mcg twice daily (combination therapy) versus FP 125 and SM 25 mcg twice daily (concurrent therapy).

\begin{tabular}{|c|c|c|c|}
\hline & FP+SM 125/25 (n=157) & $\begin{array}{l}\text { FP } 125 \text { plus SM } 25 \text { taken } \\
\text { concurrently }(n=141)\end{array}$ & P Value \\
\hline \multicolumn{4}{|c|}{ mPEFR (L/min) Mean (SD) } \\
\hline Week 3 & $319.2(78.3)$ & $324.8(87.4)$ & 0.5454 \\
\hline Week 6 & $321.9(76.91)$ & $327.8(88.68)$ & 0.4906 \\
\hline Week 9 & $323.7(77.33)$ & $331.0(87.12)$ & 0.4108 \\
\hline Week 12 & $328.1(76.86)$ & $331.3(84.25)$ & 0.7055 \\
\hline \multicolumn{4}{|c|}{$\mathrm{FEV}_{1}(\mathrm{~L})$ Mean (SD) } \\
\hline Week 3 & $1.997(0.523)$ & $2.052(0.556)$ & 0.3387 \\
\hline Week 6 & $2.016(0.529)$ & $2.059(0.558)$ & 0.4425 \\
\hline Week 9 & $2.023(0.542)$ & $2.060(0.549)$ & 0.5096 \\
\hline Week 12 & $2.032(0.555)$ & $2.064(0.544)$ & 0.5493 \\
\hline
\end{tabular}

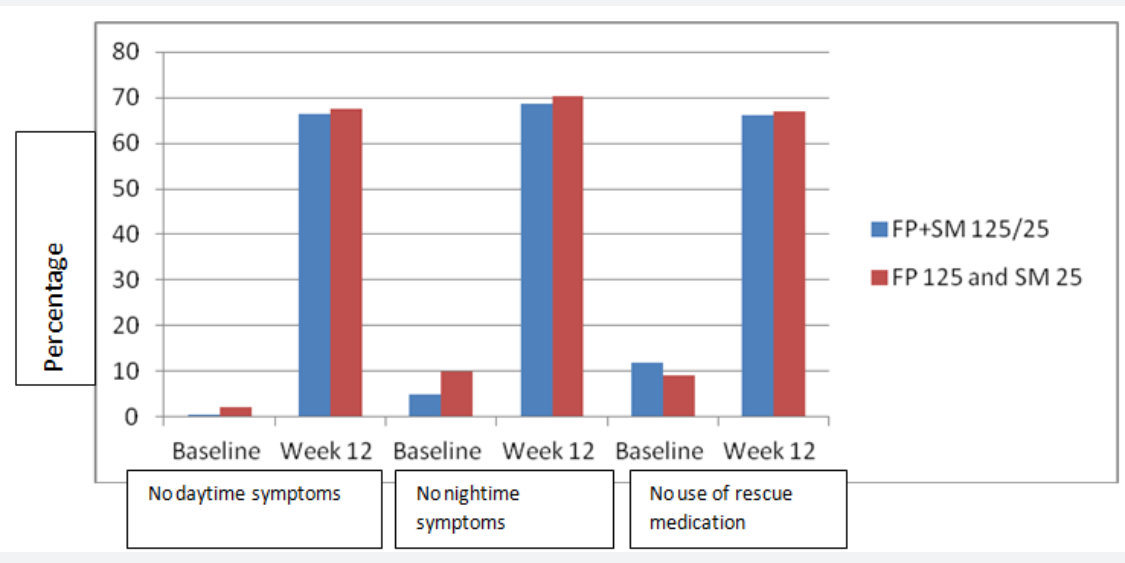

Figure 2: Mean percentage symptom-free days and nights, and rescue medication-free days and nights at baseline and after 12 weeks of treatment with either FP/SM 125/25 twice daily (combination therapy) or FP 125 plus SM 25 (concurrent therapy).

\section{Asthma symptoms}

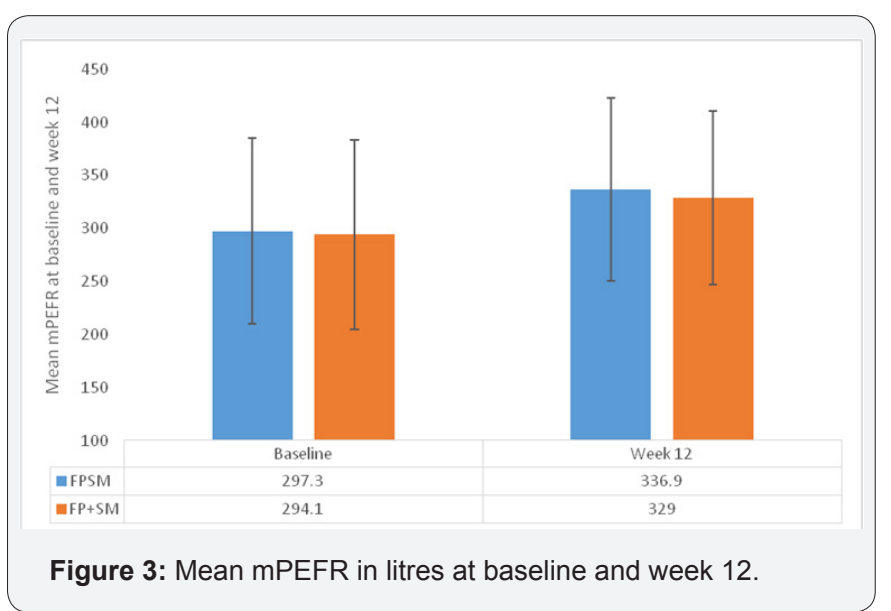

Clinically relevant improvement from baseline was also observed for median daytime and nighttime asthma symptom scores after 12 weeks of treatment in both groups. Overall, the percentages of subjects without any daytime asthma symptoms (score, 0) increased from $0.6 \%$ to $61 \%$ in the FP/SM $125 / 25 \mathrm{mcg}$ combination group and from $2.1 \%$ to $63.6 \%$ in the concurrent
FP $125 \mathrm{mcg}$ plus SM 25mcg group. Similar improvements were observed for nighttime symptoms in both groups (Figure 3). There were no differences between groups in the magnitude of improvement in either daytime or nighttime symptoms.

\section{Rescue medication use}

There was a clinically relevant decrease from baseline in rescue medication use (mean number of puffs/day) in both treatment groups (PP population) after 12 weeks of treatment (Figure 3).

\section{Tolerability}

The incidence of adverse events during the 12-week treatment period was similar for the two treatment groups, with 97 (53\%) subjects in the FP/SM 125/25 group and 83 (47\%) subjects in the FP $125+$ SM 25 group reporting any adverse event. Cough was the most common $\mathrm{AE}$ in both groups $(\mathrm{n}=27$ $(15 \%)$ with the combination treatment and $n=26(15 \%)$ with the concurrent treatment). There were 28 subjects (15\%) and 21 subjects (12\%) who reported headache and 20 subjects $(11 \%)$ and 21 subjects (12\%) reported pyrexia in the combination and concurrent treatments, respectively. 
There was one serious adverse event (acute exacerbation of asthma) occurring in the FP 125 / SM 25 mcg combination group leading to withdrawal from the study. This serious adverse event was not related to the study medication, was of moderate severity, and resolved by the end of the study. There was one subject in each treatment group (including the subject who experienced a serious adverse event) who dropped out of the study due to adverse events. Most of the AEs were of mild to moderate intensity and both treatments were generally well tolerated. No clinically significant changes from baseline were found in vital-sign measurements or laboratory tests in either group throughout the study.

\section{Discussion}

This study demonstrates that FP/SM 125/25mcg HFA pMDI is at least as effective as concurrent administration of the monocomponents from separate inhalers in improving pulmonary function ( morning PEF and $\mathrm{FEV}_{1}$ ), asthma symptom scores, and rescue medication use in subjects with persistent asthma. The improvement in symptom-related endpoints was consistent with the improvement observed with lung function parameters.

The results of this study are consistent with those reported previously for the FP/SM combination product administered via a dry powder inhaler. In these studies, the improvement in adjusted mean morning PEFR over weeks 1-12 ranged from 35 $\mathrm{L} / \mathrm{min}$ to $43 \mathrm{~L} / \mathrm{min}$ in the combination therapy $[14,15]$. However, unlike the prior studies, the current study was conducted with a MDI rather than a breath-actuated dry-powder inhaler. This is important since it has been widely established that critical errors are common with MDI use, even with training, which can lead to worsening of asthma control [17]. The fact that subjects in both groups had comparable improvements in all measures of overall asthma control indicates that subjects received adequate amounts of drug from the MDI devices used in the study.

Poor adherence with inhaled corticosteroid (ICS) therapy in asthma is a major factor contributing to poor disease control and is associated with an increased risk of morbidity and mortality [1,2] Combination metered dose inhalers that include both ICS and a LABA can potentially improve adherence and long term compliance to asthma medications [18-21]. First, the addition of a bronchodilator means the patient may obtain a symptomatic benefit and therefore take the medication that also delivers ICS more regularly. Second, it simplifies the medication regimen (compared with an ICS and LABA taken separately), an approach that has the potential to improve adherence [4,5]. In addition, there are safety concerns regarding the use of LABAs without concomitant ICS therapy in asthma [22-24] and the use of a combination inhaler ensures that subjects will not take LABAs as monotherapy. Finally, in addition to the comparable improvements in efficacy for the two treatments, the overall $\mathrm{AE}$ profiles were also comparable.

\section{Conclusion}

The results of this study indicate that in subjects with mild to moderate persistent asthma. administration of FP/SM 125/25 HFA pMDI as a combination product was at least as effective as concurrent administration of the mono-components in improving overall asthma control as assessed by lung function, asthma symptoms and rescue medication use.

\section{Acknowledgment}

This study was supported by Cipla Ltd, India.

\section{References}

1. World Health Organization (2007) Global surveillance, prevention and control of chronic respiratory diseases: a comprehensive approach.

2. Global Initiative for Asthma (GINA) Global strategy for asthma management and prevention: NHLBI/WHO Workshop Report: Bethesda: National Institutes of Health, National Heart, Lung, and Blood Institute.

3. Greening AP, Ind PW, Northfield M, Shaw G (1994) Added salmeterol versus higherdose corticosteroid in asthma patients with symptoms on existing inhaled corticosteroid. Allen \& Hanburys Limited UK Study Group. Lancet 344(8917): 219-224.

4. Bateman ED, Britton M, Carrillo J, Almeida J, Wixon C (1998) Salmeterol/Fluticasone combination inhaler: a new, effective and well tolerated treatment for asthma. Clin Drug Investig 16(3): 193-201.

5. Shrewsbury S, Pyke S, Britton M (2000) Meta-analysis of increased dose of inhaled steroid or addition of salmeterol in symptomatic asthma (MIASMA). BMJ 320(7246): 1368-1373.

6. Condemi JJ, Goldstein S, Kalberg C, Yancey S, Emmett A, et al. (1999) The addition of salmeterol to fluticasone propionate versus increasing the dose of fluticasone propionate in patients with persistent asthma. Salmeterol Study Group. Ann Allergy Asthma Immunol 82(4): 383-389.

7. Jenkins C, Woolcock AJ, Saarelainen P, Lundback B, James MH (2000) Salmeterol/fluticasone propionate combination therapy $50 / 250$ microg twice daily is more effective than budesonide 800 microg twice daily in treating moderate to severe asthma. Respir Med 94(7): 715723.

8. Murray JJ, Church NL, Anderson WH, Bernstein DI, Wenzel SE, et al. (1999) Concurrent use of salmeterol with inhaled corticosteroids is more effective than inhaled corticosteroid dose increases. Allergy Asthma Pro 20(3): 173-180.

9. Van Noord JA, Schreurs AJ, Mol SJ, Mulder PG (1999) Addition of salmeterol versus doubling the dose of fluticasone propionate in patients with mild to moderate asthma. Thorax 54(3): 207-212.

10. Woolcock A, Lundback B, Ringdal N, Jacques LA (1996) Comparison of addition of salmeterol to inhaled steroids with doubling of the dose of inhaled steroids. Am J Respir Crit Care Med 153(5): 1481-488.

11. Matz J, Emmett A, Rickard K, Kalberg C (2001) Addition of salmeterol to low-dose fluticasone versus higher-dose fluticasone: an analysis of asthma exacerbations. J Allergy Clin Immunol 107(5): 783-789.

12. Barnes PJ (2002) Scientific rationale for inhaled combination therapy with long-acting beta2-agonists and corticosteroids. Eur Respir J 19(1): 182-191.

13. Nelson HS, Chapman KR, Pyke SD, Johnson M, Pritchard JN (2003) Enhanced synergy between fluticasone propionate and salmeterol inhaled from a single inhaler versus separate inhalers. J Allergy Clin Immunol 112(1): 29-36. 
14. Aubier M, Pieters W, Schlösser NJ, Steinmetz KO (1999) Salmeterol/ fluticasone propionate $(50 / 500 \mu \mathrm{g})$ in combination in a Diskus inhaler (Seretide) is effective and safe in the treatment of steroid-dependant asthma. Respir Med 93(12): 876-884.

15. Chapman KR, Ringdal N, Backer V, Palmqvist M, Saarelainen S, et al. (1999) Salmeterol and fluticasone propionate (50/250microg) administered via combination Diskus inhaler: as effective as when given via separate Diskus inhalers. Can Respir J 6(1): 45-51.

16. Global Initiative for Asthma (GINA) (2007) Global strategy for asthma management and prevention: NHLBI/WHO Workshop Report: Bethesda: National Institutes of Health, National Heart, Lung, and Blood Institute.

17. Miller MR, Hankinson J, Brusasco V, Burgos F, Casaburi R, et al. (2005) Standardisation of Spirometry Eur Respir J 26(2): 319-338.

18. Melani AS, Bonavia M, Cilenti V, Cinti C, Lodi M, et al. (2011) Inhaler mishandling remains common in real life and is associated with reduced disease control. Respir Med 105(6): 930-938.

19. Pearlman DS, Peden D, Condemi JJ, Weinstein S, White M, et al. (2004) Efficacy and safety of fluticasone propionate/salmeterol HFA 134A MDI in patients with mild-to-moderate persistent asthma. J Asthma 41(8): 797-806
20. Bateman ED, Silins V, Bogolubov M (2001) Clinical equivalence of salmeterol/fluticasone propionate in combination $(50 / 100$ microg twice daily) when administered via a chlorofluorocarbon-free metered dose inhaler or dry powder inhaler to patients with mild-to-moderate asthma. Respir Med 95(2): 136-146.

21. Nathan RA, Rooklin A, Schoaf L, Scott C, Ellsworth A, et al. (2006) Efficacy and tolerability of fluticasone propionate/salmeterol administered twice daily via hydrofluoroalkane 134a metered-dose inhaler in adolescent and adult patients with persistent asthma: a randomized, double-blind, placebo-controlled, 12-week study. Clin Ther 28(1): 73-85.

22. Nelson HS, Wolfe JD, Gross G, Greos LS, Baitinger L, et al. (2003) Efficacy and safety of fluticasone propionate $44 \mathrm{microg} / \mathrm{salmeterol} 21$ microg administered in a hydrofluoroalkane metered-dose inhaler as an initial asthma maintenance treatment. Ann Allergy Asthma Immunol 91(3): 263-269.

23. Suissa S, Ernst P, Boivin JF, Horwitz RI, Habbick B, et al. (1994) A cohort anlaysis of excess mortality in asthma and the use of inhaled betaagonists. Am J Respir Crit Care Med 149(3): 604-610.

24. Rodrigo GJ, Castro-Rodríguez JA (2012) Safety of long-acting $\beta$ agonists for the treatment of asthma: clearing the air. Thorax 67(4): 342-349.

Your next submission with Juniper Publishers will reach you the below assets

- Quality Editorial service

- Swift Peer Review

- Reprints availability

- E-prints Service

- Manuscript Podcast for convenient understanding

- Global attainment for your research

- Manuscript accessibility in different formats ( Pdf, E-pub, Full Text, Audio)

- Unceasing customer service

Track the below URL for one-step submission https://juniperpublishers.com/online-submission.php 